\title{
The influence of high-fat, high-sugar diet and bariatric surgery on HSP70 and HSP90 plasma and liver concentrations in diet-induced obese rats
}

\author{
Dominika Stygar ${ }^{1}$ (D) Bronisława Skrzep-Poloczek ${ }^{1} \cdot$ Ewa Romuk $^{2}$ • Elżbieta Chełmecka ${ }^{3}$. Jakub Poloczek ${ }^{4}$. \\ Tomasz Sawczyn $^{1} \cdot$ Justyna Maciarz ${ }^{1} \cdot$ Michał Kukla $^{5} \cdot$ Konrad W. Karcz $^{6} \cdot$ Jerzy Jochem $^{1}$
}

Received: 27 September 2018 / Revised: 22 January 2019 / Accepted: 30 January 2019 / Published online: 6 March 2019

(C) The Author(s) 2019

\begin{abstract}
Metabolic surgery ameliorates insulin resistance and is associated with long-term, effective weight loss, but the mechanisms involved remain unknown. Here, the duodenal-jejunal omega switch (DJOS) surgery in combination with highfat, high-carbohydrate diet was performed on diet obese rats and joint effects of bariatric surgery and different dietary patterns on heat shock protein 70 (HSP70) and HSP90 plasma and liver concentrations were measured. We found that plasma and liver levels of HSP70 were lower after DJOS surgery in comparison to the control in the groups of animals kept on control diet (CD) and high-fat, high-sugar diet (HFS) but the postoperative change of the diet led to the increase in HSP70 in plasma and liver concentration in DJOS-operated animals. A high-calorie meal, rich in carbohydrates and fats, significantly increased circulating levels of HSP90, reducing the normalising effect of DJOS. The HFS diet applied during all stages of the experiment led to the higher levels of liver HSP90 concentration. The combination of CD and DJOS surgery was the most efficient in the lowering of the HSP90 liver concentration. The normalisation of circulating levels and liver concentrations of HSP70 and HSP90 may be achieved in a combination of DJOS procedure with a proper dietary plan.
\end{abstract}

Keywords Bariatric surgery $\cdot$ High-fat, high-carbohydrate diet $\cdot$ HSP70 $\cdot$ HSP90 $\cdot$ Chaperones $\cdot$ Oxidative stress

Dominika Stygar

dstygar@gmail.com

1 Department of Physiology, School of Medicine with the Division of Dentistry in Zabrze, Medical University of Silesia, Katowice, Poland

2 Department of Biochemistry, School of Medicine with the Division of Dentistry in Zabrze, Medical University of Silesia,

Katowice, Poland

3 Department of Statistics, Department of Instrumental Analysis, School of Pharmacy with the Division of Laboratory Medicine in Sosnowiec, Medical University of Silesia, Katowice, Poland

4 Department of Rehabilitation, 3rd Specialist Hospital in Rybnik, Rybnik, Poland

5 Department of Gastroenterology and Hepatology, School of Medicine in Katowice, Medical University of Silesia, Katowice, Poland

6 Clinic of General, Visceral, Transplantation and Vascular Surgery, Hospital of the Ludwig Maximilian University, Munich, Germany

\section{Introduction}

The complex pathophysiology of obesity represents a challenge for the mechanistic understanding of the action of different stimuli on the human body and of their possible role in metabolic distress. Oxidative stress, under the conditions of obesity, is one of the early events in the development of metabolic syndrome (Aroor and DeMarco 2014, Furukawa et al. 2004). Heat shock proteins (HSPs) are a family of stressresponsive proteins that modulate cell function and contribute to protein homeostasis (Atalay et al. 2009, Asea 2008). The HSP70 is a class of highly abundant and ubiquitously expressed chaperones that participate in protein trafficking, early stages of nascent polypeptide folding and the refolding or degradation of aggregated peptide products (Lackie et al. 2017, Bukau et al. 2006). In the situation, when correct folding of the client proteins is not possible, HSP70 association with additional co-chaperones promotes degradation of the misfolded protein (Lackie et al. 2017). Nakhjavani et al. reported previously that the serum level of plasma extracellular 
HSP70 (eHSP70) was significantly higher in long-term type 2 diabetes mellitus patients in comparison to the newly diagnosed subjects and the higher eHSP70 levels were inversely correlated with fasting blood glucose concentration (Nakhjavani et al. 2010). High HSP70 plasma levels are associated with the inhibition of nitric oxide synthase (NOS) under inflammatory conditions in T2DM (Nakhjavani et al. 2012). HSP70 plasma levels were also increased in diabetic nephropathy, as a response to the oxidative damage (Morteza et al. 2013). Plasma HSP70 concentrations in gestational diabetes correlate well with the levels of glycated haemoglobin (HbA1c) (Garamvölgyi et al. 2015).

In eukaryotic cells, HSP90 clients are, among others, the key mediators of signal transduction and transcriptional regulation (e.g., NF-кB, STATs, p53) and kinases (e.g., Raf/MEK/ ERK, PI3K/AKT, p38/MAPK). Thus, HSP90 plays a central role in processes like inflammation, growth, survival, differentiation and apoptosis (Trepel et al. 2010; Pratt and Toft 2003). Increased levels of HSP90 have been observed in malignant cells and inflamed tissues, and that is why HSP90 is particularly studied in the context of the treatment of cancer and autoimmune/inflammatory diseases (Ambade et al. 2014; Shukla and Pitha 2012; Li et al. 2013; Tukaj et al. 2013). HSP90 has been targeted as a new therapeutic approach in hepatocellular carcinoma (HCC) (Breinig et al. 2009) and fibrosis (Myung et al. 2009).

Aside from sustained weight loss, bariatric surgery helps to regulate metabolic processes leading to normalisation of glucose tolerance, insulin sensitisation and increasing energy expenditure (Rubino et al. 2006; Buchwald et al. 2004; Rubino et al. 2010; Stefater et al. 2012). Spectacular effects of bariatric surgery in long-term body weight reduction and glucose tolerance amelioration in obese individuals have stimulated the development of new surgical techniques (Kahn et al. 2006, Karcz et al. 2013). Duodenal-jejunal omega switch (DJOS), as used here, is a bariatric procedure, where a proximal loop duodeno-enterostomy is used to bypass the foregut and allows for direct hindgut stimulation (Nauck 2009; Rubino and Gagner 2002). DJOS as a relatively new technique still needs to be studied in order to assess its long-term pathophysiological effects (Grueneberger et al. 2014; Traverso and Longmire Jr 1978). Therefore, here, an animal model is used in order to address questions regarding the effects of DJOS that could not be pursued experimentally in humans.

Dietary patterns play a significant role in the aetiology and prevention of risk factors like metabolic syndrome, T2DM and obesity (O'Keefe et al. 2008). A high-fat diet leads to disturbances in the expression of inflammatory factors and can deregulate adaptive immunity in obesity (Makki et al. 2013; Rocha et al. 2008). Long-term ingestion with a highcaloric diet interferes with insulin signalling pathways, leads to the increase in peripheral insulin resistance and immune disorders (Cancello and Clément 2006). The high-fat, high- sugar diet (HFS) adopted in this experiment is known to develop hypertension, impaired glucose tolerance, higher abdominal fat deposition, increased abdominal circumference and an altered lipid profile (Poudyal et al. 2010). The digestion of different types of dietary products has different effects on the metabolism, including the expression of Hsps. No reports were found in the literature regarding the effects of an HFS diet and bariatric surgery on HSP70 and HPS90 plasma and liver levels. Thus, the aim of this study was to assess the effect of the DJOS procedure combined with a high-fat, highcarbohydrate diet on HSP70 and HSP90 plasma and liver concentrations in diet-induced obese rats.

\section{Materials and methods}

\section{Animals and diets}

All experimental procedures were approved by the Local Ethics Committee, Katowice, Poland (58/2014). The methodology of DJOS was previously described by Karcz et al. 2013 and Stygar et al. 2018. Forty-eight male Sprague-Dawley rats, initially weighing between 250 and $275 \mathrm{~g}$, were purchased from the Center for Experimental Medicine, Medical University of Silesia, Katowice, Poland. Animals were housed in plastic cages under controlled conditions (ambient temperature, $23{ }^{\circ} \mathrm{C} ; 12 \mathrm{~h}$ light/dark cycle, lights on 6:00 AM to 6:00 PM). All rats had free access to water and food. The control group was maintained on a professional, regular diet (Provimi Kliba AG, Kaiseraugst, Switzerland, 24\% protein, $4.9 \%$ fat, $7 \%$ crude ashes, $4.7 \%$ crude fibre). Obesity was induced by keeping the animals on an HFS diet (HFS $22.0 \mathrm{MJ} / \mathrm{kg}, 45 \%$ fat, $35 \%$ carbohydrate and $20 \%$ protein (ssniff® EF R/M acc. D12451 (II) mod., Ssniff Spezialdiäten $\mathrm{GmbH}$, Germany) for the period of 2 months before and after the surgery. All rats fasted overnight before surgery.

\section{Experimental design}

After 1 week of acclimatisation, the rats were allocated to the experimental groups: HFS diet $(n=28)$ and control diet (CD) $(n=28)$. The total length of the experiment was 16 weeks. For 8 weeks before and after the DJOS/SHAM surgery, the animals were maintained on their allocated diets. The initial part of the procedure, prior to the surgery, included 8 weeks of maintenance on experimental diets. Following this period, both groups were further split into subgroups, which then underwent two separate types of surgery: SHAM $(n=14)$ or DJOS ( $n=14$, Fig. $1 \mathrm{a}-\mathrm{c}$ ).

For the second stage of the experiment, through the 8 weeks following the surgery, seven animals from the DJOS and SHAM groups were maintained on the same diet as prior to the surgery taking place (HFS/DJOS/HFS, HFS/SHAM/HFS, 
a High Sugar Diet

\begin{tabular}{c|c}
\hline placebo surgery & duodeno-jejunostomy \\
\hline DIOS & SHAM \\
\hline - Control Diet & -Control Diet \\
-HFS Diet & -HFS Diet
\end{tabular}

\section{Control Diet}

\begin{tabular}{|l|l}
\hline placebo surgery & duodeno-jejunostomy \\
DIOS & SHAM \\
:Control Diet & $:$ Control Diet \\
:HFS Diet & :HFS Diet
\end{tabular}

b



C

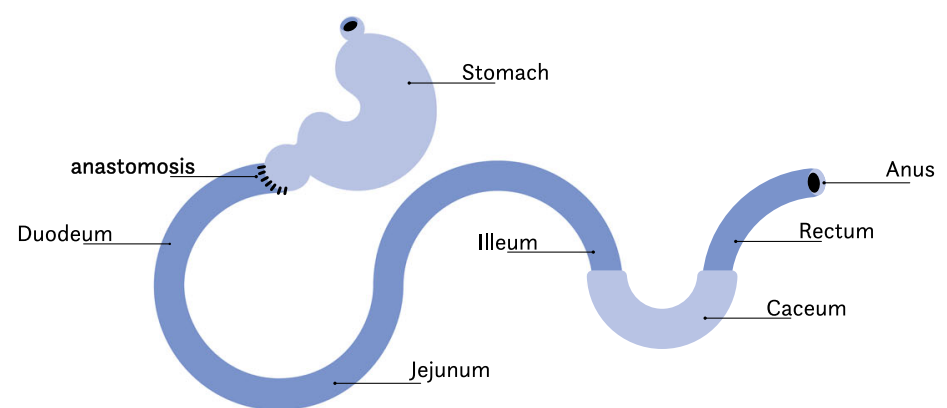

Fig. 1 Scheme of the experiment. a Dietary patterns used pre- and post-surgery. b DJOS procedure. c SHAM procedure

$\mathrm{CD} / \mathrm{DJOS} / \mathrm{CD}, \mathrm{CD} / \mathrm{SHAM} / \mathrm{CD})$, and a further seven from each group had an altered diet (HFS/DJOS/CD, HFS/ SHAM/CD, CD/DJOS/HFS, CD/SHAM/HFS; Fig. 1a). The number of rats included in the research was minimalised in consideration of the '3Rs' for the humane treatment of animals (Russell and Burch 1959). The survival rate of animals during the experiment and post-surgery was $100 \%$.

\section{Experimental procedures}

The DJOS was performed according to Karcz et al. (Karcz et al. 2013), described in the aforementioned study (Stygar et al. 2018). To perform DJOS, the animals were anaesthetised with 2\% isoflurane (AbbVie Deutschland GmbH \& Co. KG, Ludwigshafen, Germany) and oxygen flow at $21 / \mathrm{min}$ under spontaneous breathing. Analgesia with xylazine $(5 \mathrm{mg} / \mathrm{kg}$, ip; Xylapan, Vetoquinol Biovet, Poland) and antibiotic prophylaxis with gentamicin (40 mg/ml, Krka, Poland) was applied. In order to gain abdominal access, a midline incision of 3$4 \mathrm{~cm}$ was performed, and the total length of the small intestine was determined. The stomach was separated from the duodenum at the point just below the pylorus and the position of anastomosis was defined as being at $1 / 3$ of the total small bowel length. The jejunum was anastomosed via end-to-side duodeno-enterostomy in order to restore the physiological conduit of the food passage, excluding the duodenum and parts of the small intestine. The remaining duodenal stump was closed using PDS 6/0 (Ethicon, US, LLC). Mesenteric openings were closed with PDS 6/0 (Ethicon, US, LLC). In the SHAM-operated animals, reanastomosis of the gastrointestinal tract was performed at the corresponding sites where enterotomies were performed for the duodenojejunostomy, thereby maintaining continuity of the food passage through the bowel (Fig. 1b, c). For DJOS and SHAM protocols, postoperative analgesia was performed using carprofen $(4 \mathrm{mg} / \mathrm{kg}$, sc; Rimadyl, Pfizer, Switzerland) for three consecutive days after the surgery.

Tissue collection and HSP70 and HSP90 ELISA analysis

At the end of the 8 th week after surgery, corresponding to the 16th week of the experiment, the tissue samples for HSP measurements were collected. The animals were anaesthetised with $2 \%$ isoflurane and oxygen flow at $2 \mathrm{l} / \mathrm{min}$ under spontaneous breathing. Analgesia was conducted with xylazine. Blood samples were collected from the abdominal aorta, using tubes containing $10 \mu \mathrm{l}$ EDTA (Sigma-Aldrich, St. Louis, MO). After centrifugation at $4000 \mathrm{rpm}$ for $10 \mathrm{~min}$ at $4{ }^{\circ} \mathrm{C}$, plasma samples were collected, snap-frozen in liquid nitrogen and stored at $-80^{\circ} \mathrm{C}$ until analyses were performed.

Liver tissues were harvested and the animals were subjected to euthanasia. Tissue samples were prepared by homogenisation and sonification ( $15 \mathrm{~s}$ ) on ice, in a tissue cell lysis buffer containing protease inhibitors (Gold Bio Technology, USA, MO). After that, the homogenates were centrifuged at $15,000 \mathrm{~g}$ for $15 \mathrm{~min}$ at $4{ }^{\circ} \mathrm{C}$. Homogenates were snap-frozen in liquid nitrogen and stored at $-80{ }^{\circ} \mathrm{C}$ until further analysis. HSP70 plasma and liver concentrations were measured using the rat HSP70 enzyme-linked immunosorbent assay (ELISA) Kit (Enzo Life Sciences, Inc., NY; ADI-EKS-715). The smallest concentration of a HSP70 that could be reliably measured by selected analytical Kit was $90 \mathrm{pg} / \mathrm{ml}$, with detection range $0.20-12.5 \mathrm{ng} / \mathrm{ml}$; ADI-EKS-700B, minimum sensitivity $200 \mathrm{pg} / \mathrm{ml}$ (detection range $780-50,000 \mathrm{pg} / \mathrm{ml}$ ) according to the manufacturer's instructions. HSP90 plasma and liver concentrations were measured using the rat HSP90 ELISA 
(Wuhan USCN Business Co., Ltd. Product no SEA823Ra). The smallest concentration of a HSP90 that could be reliably measured by selected analytical Kit was $0.055 \mathrm{ng} / \mathrm{ml}$, with detection range $0.156-10 \mathrm{ng} / \mathrm{ml}$. Each experiment was performed in duplicate.

\section{Statistical analysis}

Statistical analysis was performed using STATISTICA 13.1 PL (StatSoft, Cracow, Poland). All tests were two-tailed and statistical significance was set at a $p$ value below 0.05 . Interval data were expressed as mean value \pm standard deviation. Distribution of variables was evaluated by the Shapiro-Wilk test and the quantile-quantile plot; homogeneity of variances was assessed by Levene's test. For comparison of data, the two-way parametric ANOVA with post hoc contrast analysis was used.

\section{Results}

Table 1 shows the measured plasma concentrations of HSP70 and HSP90 and the HSP70 and HSP90 liver concentrations of rats that underwent DJOS or SHAM surgery. For the analysed HSP70, the plasma concentrations and liver levels were not related to DJOS and SHAM surgery, and were related to the interaction between surgery and the type of diet applied before/after surgery. Table 1 also shows differences in HSP90 plasma and the liver tissues of animals after both types of surgery. The impact of the type of surgery on HSP90 plasma and HSP90 liver levels is different than in the HSP70 analysis where the impact of surgery was not observed. In all analysed DJOS study groups, the HSP90 levels were significantly different, except for the comparison of the groups where diet was changed after surgery (CD/HFS and HFS/CD). In those groups, HSP90 plasma levels were similar and significantly higher when compared to the $\mathrm{CD} / \mathrm{CD}$ group but significantly lower when compared to the HFS/HFS group. A similar situation is observed in SHAM-operated groups where significant differences between the groups were observed. Significant differences were deduced from two-way ANOVA analysis between the type of surgery, groups and interaction between group and operation type. When the two-way analysis of variance shows that one of the main analysed factors is statistically significant, and when alsobut not necessarily - an interaction between two main factors occurs, then contrast analysis can be performed. This means that we can compare each subclass of the first factor between groups defined by the first factor ( $p$ value for comparisons between types of operation, SHAM and DJOS), and each subclass of the second factor between groups defined by the first factor ( $p$ value for comparisons between diets, i.e. HF/

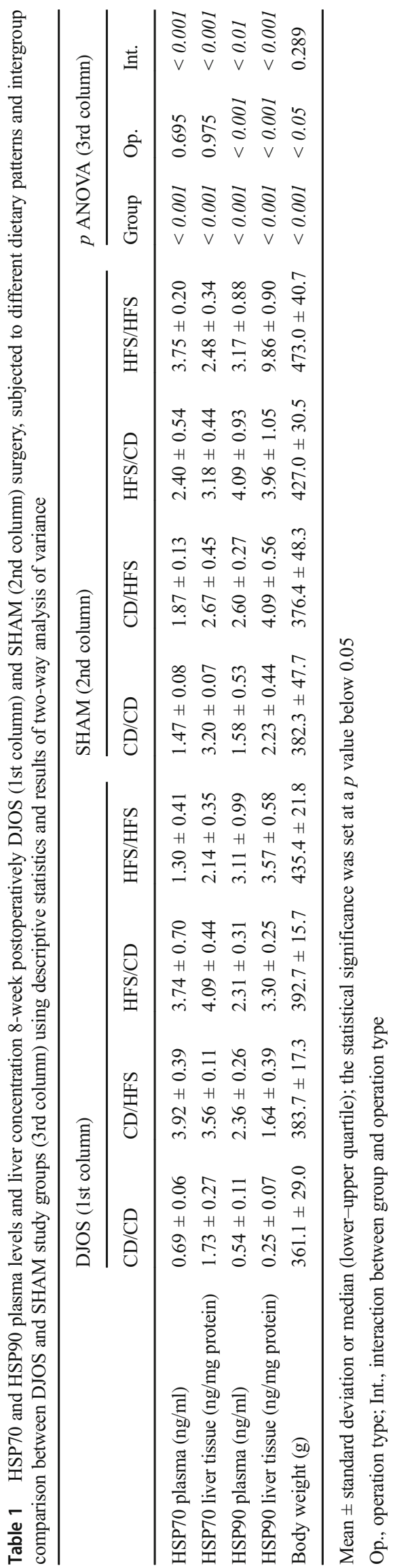


$\mathrm{HF}$; $\mathrm{HF} / \mathrm{CD} ; \mathrm{CD} / \mathrm{HF} ; \mathrm{CD} / \mathrm{CD}$ ). Multiple comparisons, in contrast analysis of HSP plasma and liver levels in DJOS and SHAM-operated groups in relation to the diet used before and after surgery, are presented in Table 2. Column 1 shows a comparison between DJOS and SHAM surgery associated with different diets, column 2 shows comparisons between dietary groups of DJOS animals, and column 3 shows comparisons between dietary groups of SHAM animals.

\section{HSP70 plasma and liver concentrations}

The plasma levels and liver concentrations of HSP70 were significantly related to the type of diet and interaction between the diet and surgery but not to the surgery itself (Fig. 2; Tables 1 and 2).

DJOS vs SHAM Significant differences in the HSP70 plasma levels were observed for all analysed study groups (Fig. 2; Tables 1 and 2). For HSP70 liver concentration, significant differences between $\mathrm{CD} / \mathrm{CD}, \mathrm{CD} / \mathrm{HFS}$ and HFS/CD groups were observed (Fig. 2; Tables 1 and 2).

DJOS surgery After DJOS surgery, the plasma level and liver concentrations of HSP70 were significantly higher in the groups, where the diet was changed after the surgery $(\mathrm{CD} /$ HFS and HFS/CD) when compared to the groups, which remained on an unchanged diets (HFS/HFS, CD/CD) (Figs. 2 and 3; Tables 1 and 2).

SHAM surgery In the SHAM-operated animals, the level of HSP70 in plasma was significantly increasing in the following groups: $\mathrm{CD} / \mathrm{CD}$ vs $\mathrm{CD} / \mathrm{HFS}$ vs HFS/CD vs HFS/HFS (Fig. 2; Tables 1 and 2), with the lowest values of plasma HSP70 in the $\mathrm{CD} / \mathrm{CD}$ group (Fig. 2; Tables 1 and 2). The HSP70 liver concentrations were the highest in the $\mathrm{CD} / \mathrm{CD}$ and HFS/CD groups. The value of this parameter was significantly reduced in the $\mathrm{CD} / \mathrm{HFS}$ group when compared to $\mathrm{CD} / \mathrm{CD}$ one. The liver HSP70 concentration was significantly higher in HFS/ $\mathrm{CD}$ group when compared to CD/HFS and HFS/HFS ones (Fig. 3; Tables 1 and 2).

\section{HSP90 plasma concentrations}

The plasma and liver concentrations of HSP90 were significantly dependent on the type of diet used in the experiment, the type of surgery and interactions between both types of parameters (Table 1).

DJOS vs SHAM A comparison of HSP90 plasma concentrations collected from DJOS and SHAM-operated animals shows significant differences between $\mathrm{CD} / \mathrm{CD}$ and HFS/CD groups, where values of HSP90 were higher in the samples

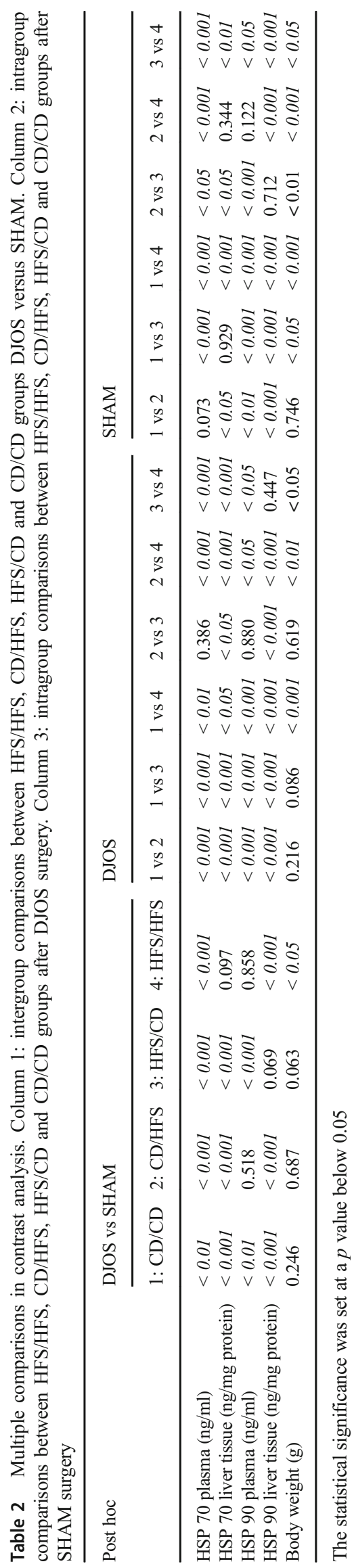




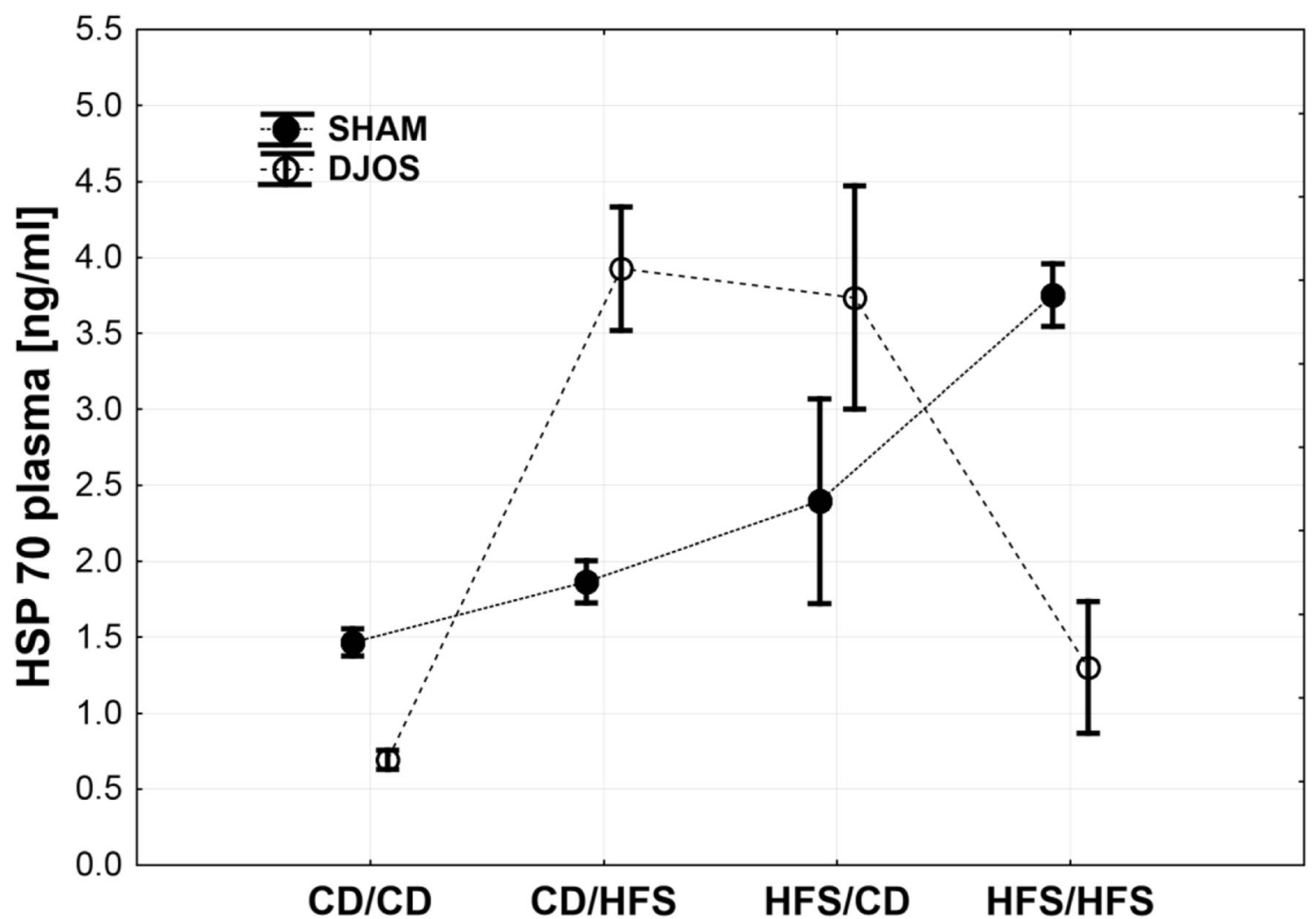

Fig. 2 Comparison of HSP70 plasma levels (ng/ml) in SHAM and DJOS-operated groups subjected to the different dietary patterns pre- and postsurgery. Abbreviations: CD, control diet; HFS, high-fat, high-sugar diet. Vertical lines depict $95 \%$ confidence interval

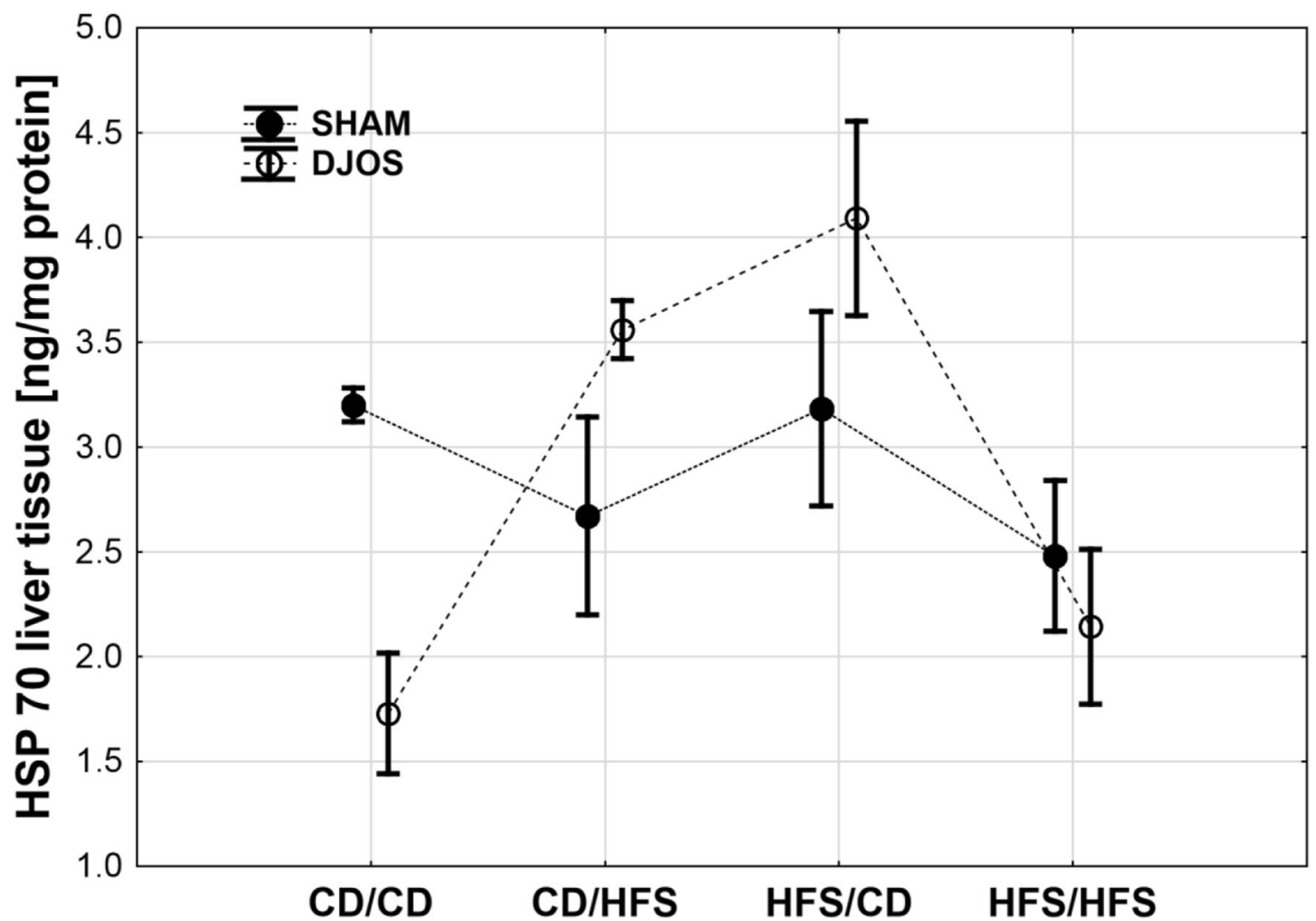

Fig. 3 Comparison of HSP70 liver concentration (ng/mg) in SHAM and DJOS-operated groups subjected to the different dietary patterns pre- and postsurgery. Abbreviations: CD, control diet; HFS, high-fat, high-sugar diet. Vertical lines depict $95 \%$ confidence interval 
collected from the SHAM-operated animals (Fig. 4; Tables 1 and 2).

DJOS surgery After DJOS surgery, the lowest values of plasma HSP90 levels were observed in the $\mathrm{CD} / \mathrm{CD}$ group when compared to other diet and surgery combinations (Fig. 4; Tables 1 and 2). The combinations of HFS diet (HFS/CD, HFS/HFS) applied before and after the surgery led to an increase in HSP90 plasma levels when compared to the CD/CD and $\mathrm{CD} / \mathrm{HFS}$ groups.

SHAM surgery In the SHAM-operated animals, similarly to the DJOS groups, a change of the diet from CD before or after surgery to the HFS diet led to a significant increase in plasma HSP90 levels (Fig. 4; Tables 1 and 2).

\section{HSP90 liver concentrations}

The HSP90 liver concentration was related to the type of studied diet, type of surgery and interaction between those parameters (Table 1).

DJOS vs SHAM The liver concentration of HSP90 was significantly higher in SHAM-operated animals in comparison to DJOS-operated rats except for HFS/CD groups (Table 1).
DJOS surgery In the DJOS-operated animals, the change of the dietary pattern from CD to HFS after the surgery or application of an HFS diet before and after surgery led to a significant increase in the HSP90 liver concentration (Fig. 5; Tables 1 and 2). The lowest HSP90 level was observed in the combinations with CD before/after the surgery, and the highest in the presence of an HFS diet during all experiments (Fig. 5; Tables 1 and 2).

SHAM surgery A similar pattern of HSP90 liver concentrations was also observed in SHAM-operated groups, with the lowest values in the $\mathrm{CD} / \mathrm{CD}$ group and increasing from the $\mathrm{CD} / \mathrm{HFS}$ to HFS/CD and to HFS/HFS groups (Fig. 5; Tables 1 and 2). There were no significant differences when comparing the $\mathrm{CD} / \mathrm{HFS}$ and HFS/CD groups.

\section{Body weight}

The type of dietary pattern and type of surgery applied had a significant impact on the body weight of animals from the analysed study groups (Tables 1 and 2).

DJOS vs SHAM All the groups that consumed an HFS (HFS/ HFS) diet had a significant increase in body weight when compared to the control group $(\mathrm{CD} / \mathrm{CD})$. The body weight of animals maintained on an HFS diet before and after the

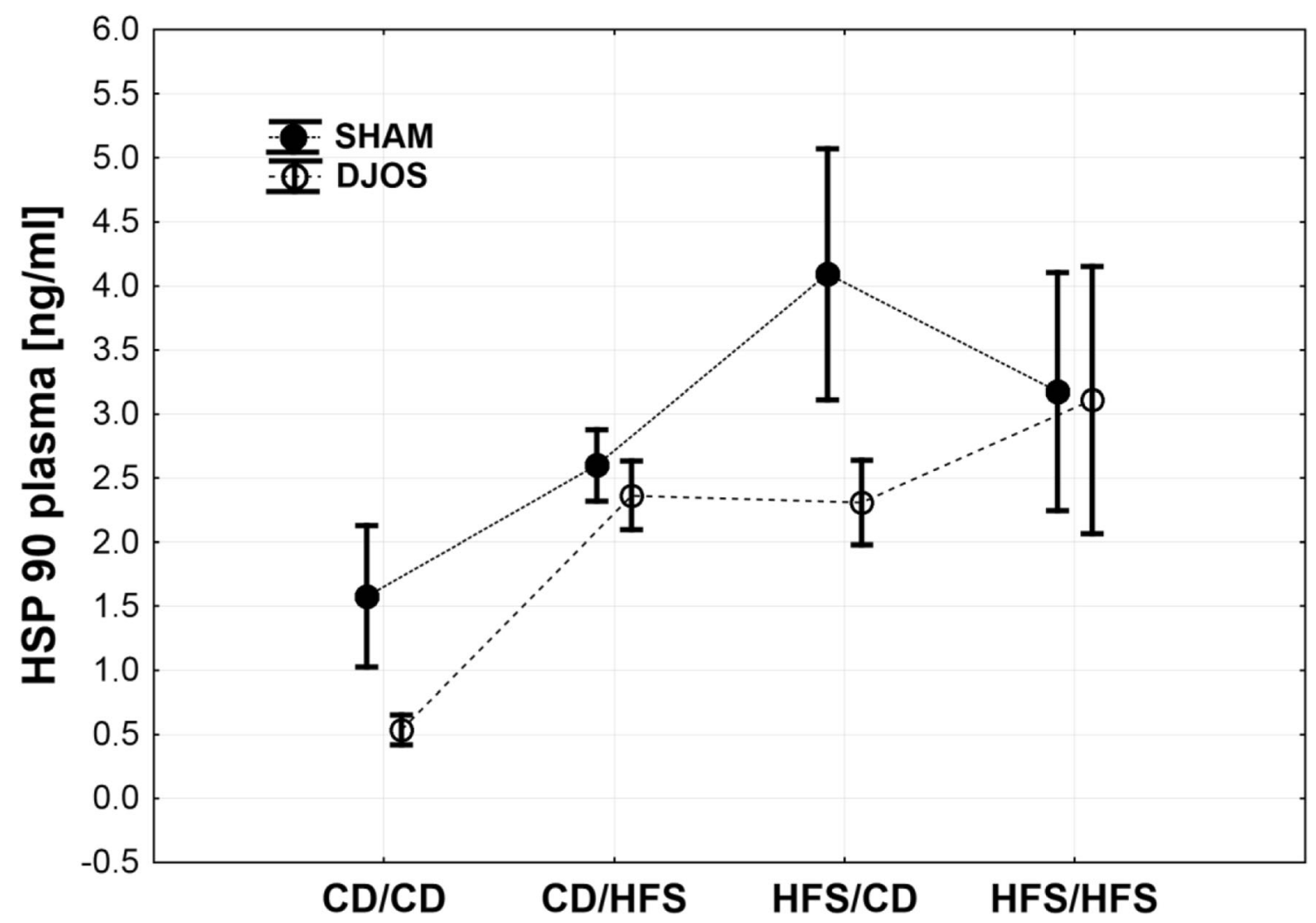

Fig. 4 Comparison of HSP90 plasma levels (ng/ml) in SHAM and DJOS-operated groups subjected to the different dietary patterns pre- and postsurgery. Abbreviations: CD, control diet; HFS, high-fat, high-sugar diet. Vertical lines depict $95 \%$ confidence interval 




Fig. 5 Comparison of HSP90 liver concentration (ng/mg) in SHAM and DJOS-operated groups subjected to the different dietary patterns pre- and postsurgery. Abbreviations: CD, control diet; HFS, high-fat, high-sugar diet. Vertical lines depict $95 \%$ confidence interval

surgery was significantly higher in the SHAM-operated animals when compared to DJOS (Fig. 6; Tables 1 and 2).

DJOS surgery After DJOS, the body weight in HFS/HFS group was significantly higher in relation to $\mathrm{CD} / \mathrm{CD}$ animals. The dietary pattern which included a CD before and an HFS diet after the surgery influenced the body weight of DJOSoperated animals in comparison to the HFS/HFS diet profile.

SHAM surgery After SHAM surgery, the animals kept on HFS/ HFS expressed the highest body weight when compared with the $\mathrm{CD} / \mathrm{CD}, \mathrm{CD} / \mathrm{HFS}$ and HFS/CD groups. The usage of HFS before the surgery significantly increased the body mass in comparison to the $\mathrm{CD} / \mathrm{CD}$ group in SHAM-operated animals.

As we reported before (Stygar et al. 2018), a change of diet to a more caloric one after DJOS surgery did not lead to significant weight loss when the surgery was not combined with gastric restriction. In our study, we observed that a high-caloric diet reduced the effects of the surgery, in contrast with other reported types of surgical procedures (Mosinski et al. 2016).

\section{Discussion}

The objective of this study was to assess the effect of bariatric surgery combined with different dietary patterns on HSP70 and HSP90 plasma and liver concentrations. A combination of high-fat, high-sugar diet was used to mimic human nutritional patterns that have been associated with the development of the metabolic syndrome, obesity and T2DM. We report that (i) plasma and liver HSP70 levels were not related to the type of surgery but were related to the type of diet and interaction between diet and surgery; (ii) HSP70 concentrations were lower after DJOS bariatric surgery in comparison to the SHAM surgery in the groups of animals kept on CD and HFS diet pre- and postoperatively; (iii) the change of the diet, regardless of the type of diet (CD/HFS or HFS/CD), was a strong stimulus for HSP70 induction in plasma and liver tissue in DJOS-operated animals when compared to SHAM groups; (iv) plasma and liver HSP90 levels are related to the type of diet and type of surgical intervention; (v) the DJOS procedure reduced HSP90 plasma levels when combined with the $\mathrm{CD}$ before and/or after the surgery, and in the presence of the HFS/ CD dietary pattern; (vi) a high-calorie meal, rich in carbohydrates and fats significantly increased plasma levels of HSP90 in the CD/HFS, HFS/CD and HFS/HFS groups, reducing the normalising effect of DJOS; (vii) the DJOS surgery and CD diet showed a strong reductive impact on HSP90 liver concentration when compared to the SHAM-operated animals; (viii) the HFS diet applied during all stages of the experiment led to the highest levels of liver HSP90 concentration; (ix) the interaction between $\mathrm{CD}$ and DJOS surgery was the most 
Vertical lines depict $95 \%$ confidence interval

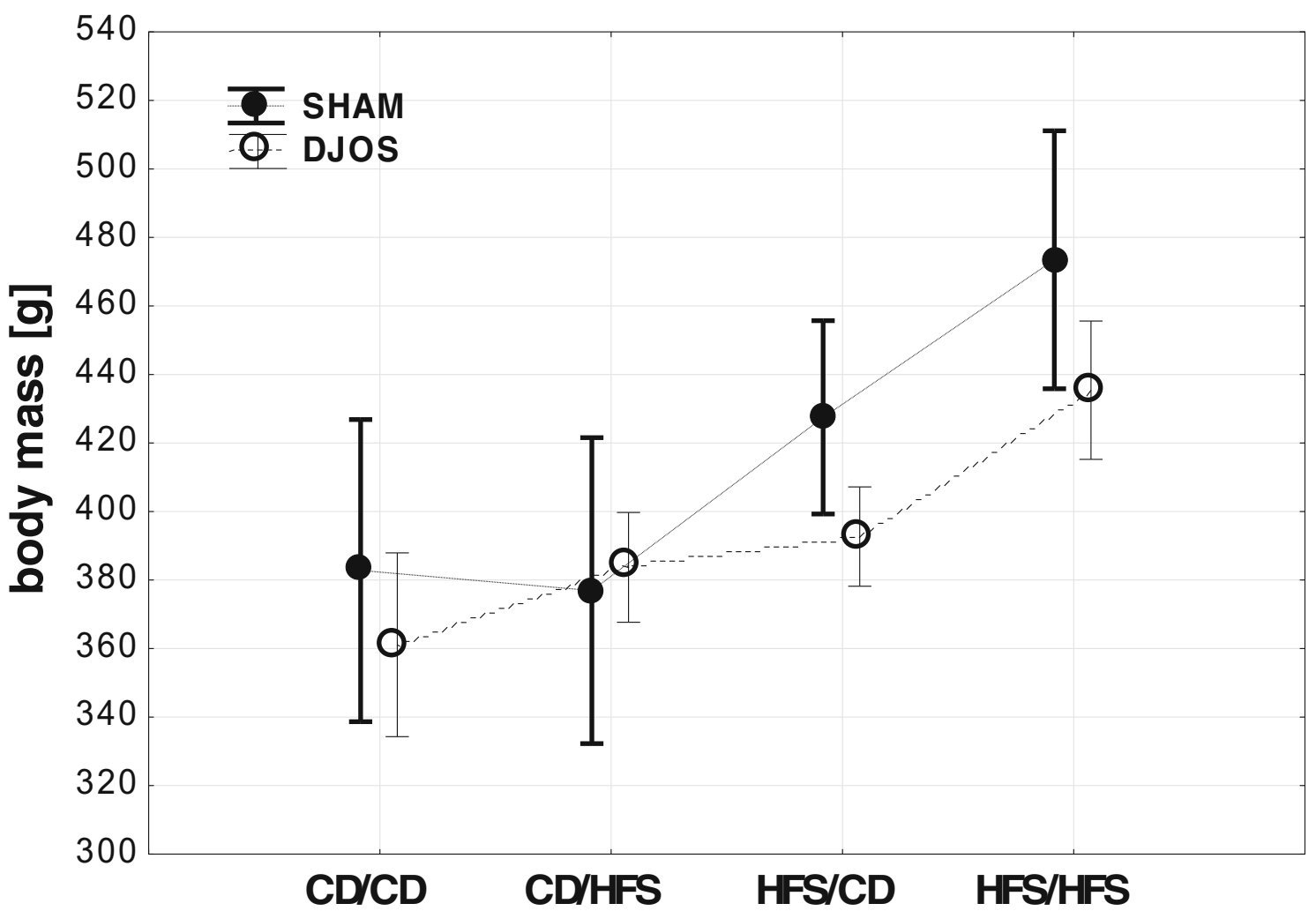

Fig. 6 Body mass (g)

efficient at lowering the HSP90 liver concentration in comparison with other dietary patterns.

The present study compares the joint therapeutic responses from the combination of diets and bariatric surgery measured by HSP70 and HSP90 levels. The obtained results suggest that the combination of DJOS and a change of the diet was a strong stimulus for HSP70 level induction in plasma and liver tissue. In our previous study, we reported increased HSP70 plasma levels after the ileal transposition (IT) in comparison to SHAM-operated, diabetic fatty Zucker rats (Stygar et al. 2015). Angelini and co-workers showed that duodenaljejunal bypass surgery leads to a decrease in levels of plasma HSP70 in obese, insulin-resistant (IR) and nonalcoholic fatty liver disease (NAFLD) subjects (Angelini et al. 2018). Serum HSP70 and plasma eHSP70 levels are known to be elevated in diabetic patients in comparison to normal subjects and correlate with diabetes duration (Nakhjavani et al. 2010). High HSP70 plasma levels are also associated with inflammatory and oxidative stress conditions in T2DM (Nakhjavani et al. 2012, Morteza et al. 2013). Circulating HSP70 levels in gestational diabetes correlate with the levels of glycated haemoglobin (HbAlc) (Garamvölgyi et al. 2015). Alemi and co-authors (Alemi et al. 2018) showed a positive relation between eHSP70 and HOMA-IR but not BMI in patients with T2DM, regardless hs-CRP levels and obesity. These results suggest the role of eHSP70 in the pathogenesis of T2DM and insulin resistance. Angelini et al. 2018 presented a study where a high-energy, high-carbohydrate and high-fat diet can trigger hypersecretion of heat shock proteins from the small intestine that can lead to insulin resistance through inhibition of Akt phosphorylation, insulin-mediated GLUT translocation on the cell membrane and ectopic intracellular fat accumulation with NAFLD development. Heydari et al. 1993 reported that the induction of hsp70 synthesis, mRNA levels and nuclear transcription were significantly higher in hepatocytes isolated from old rats fed the calorie-restricted diet than in hepatocytes isolated from old rats fed ad libitum. Since those two studies of Angelini et al. (2018) and Heydari et al. (1993) were conducted in vivo and in vitro, different parameters were measured. We would suggest that both types of described situations: the caloric limitation and a highenergy diet are strong stressors which lead to the recognised answer in the antioxidant defence system, measured by HSPs levels or hsps expression. This can be understood as a type of adaptive reaction, which leads to compensation.

Here, we report that the plasma and liver HSP70 levels were not related to the type of surgery SHAM or DJOS; nevertheless, they were related to the type of diet and the interaction between surgery and dietary pattern. It was observed that the animals, which remain on the same type of diet before and 
after DJOS surgery (CD/CD, HFS/HFS), showed lower plasma and liver HSP70 concentrations in comparison to groups where the diets were changed after DJOS surgery (CD/HFS and HFS/CD). We suggest that the change of diet, and hence the consumption of a different types of nutrients, influenced the biochemical pathways, causing perturbations and irregularities in substrate catabolism, which is also manifested in HSP production. Nevertheless, in order to confirm this thesis, additional assessments should be provided.

The limitation in caloric supply has been consistently recognised to prolong the life of mammals. Based on the fact that caloric restriction increases the longevity of rodents by altering the ageing process and augments the maximum survival of animals, Heydari et al. reported that reduction of the caloric intake increased $h s p 70$ gene expression in isolated hepatocytes of old rats, reversing the age-related deficit in the ability of the hepatocytes to respond to heat stress (Heydari et al. 1993). de Moura and co-authors presented a study, where the consumption of whey protein in the hydrolysed form (WPH), used as a source of protein, was able to increase the expression of $h s p 70$ in the lungs, soleus and gastrocnemius muscles of rats subjected to thermal stress from exercise (Moura et al. 2013). The HSPs family is highly expressed under stress conditions that augment cell tolerance and reduces the adverse effects of sudden, strong and negative stimulation. An antioxidative/prooxidative imbalance caused by a high-fat diet or changes in the nutritional status of diet deficiency, as well as a plethora of selected nutrients, influence the HSP70 and HSP90 concentrations. Changes in the Se, Mn and glutamine levels increased the quantity of $h s p 70$ and hsp90 expression. Oral supplementation with arginine enhanced muscle $h s p 70$ and $h s p 90$ expression in rats when compared to leucine, isoleucine or valine, under stress conditions produced by exercise (Moura et al. 2018). In our study, the lowest plasma levels of HSP70 and HSP90 were in the groups submitted to unchanged CD or HFS diet during all stages of the experiment. This goes along with results showing that low levels of HSP expression occur in normal physiological conditions (constitutive expression), making up 5-10\% of the total protein content in healthy growth conditions (Whitley et al. 1999). It is also known that diet-induced obesity can reduce the expression of HSPs, while the increase of HSP expression can prevent or reduce the damage caused by obesity, promoting an improvement in insulin sensitivity, glucose tolerance, inflammation reduction and an increase in insulin signalling (Henstridge et al. 2014, Chung et al. 2008, Gupte et al. 2009; Moura et al. 2018). These scientific reports regarding HSP levels and hsps gene expression in different pathological situations and stimulation are many times confusing and contradictory. We assume that the answer of the system measured by HSPs depends on the intensity of the stimulation, its duration and character of the general stressor. Thus, different and even contradictory results may be obtained and in order to achieve proper understanding and interpretation of this phenomenon other, more detailed study needs to be performed. Our study suggests that animals exposed to the change of diet after DJOS, but not SHAM, expressed the highest capacity for induction of HSP70, which is a highly active protein and complementary to the antioxidant system, when compared to animals maintained on the same type of diet before and after the surgery (Silver and Noble 2012). In relation to the control groups, the HSP70 plasma levels were significantly increased when the HFS diet was used before and/or after surgery. It was indicated that HSP70 is strongly induced by different types of stress, while its expression is very low or undetectable under conditions of normal homeostasis (Rohde et al. 2005). We would predict that the change of the diet per se and thereby the intake of the different types of nutrients together with DJOS procedure affects the biochemical pathways, leading to increased stress and changes in substrate catabolism, which is also associated with the induction of HSP70. We assume that the exclusion of the proximal part of the small intestine, performed in DJOS, may be more influential than a SHAM procedure. It can be suggested that the DJOS procedure stimulated the blood and liver cells' protective mechanisms, measured by HSP70 levels, in strong relation to the type of nutritional pattern applied before and after bariatric surgery. Modification of the diet from CD to HFS and vice versa may be considered a less suitable method of treatment and remaining on the stable diet, preferably the control one following bariatric surgery would be suggested. We also showed that exposure to the type of the surgical stress applied in this study did not influence HSP70 plasma and liver concentrations, and interaction between the type of surgery and diet was strong drivers regulating HSP70 response.

HSP90 is a chaperone protein, constitutively expressed in eukaryotic cells, and crucial for its physiological activity. It is estimated that HSP90 represents 1 to $2 \%$ of cell proteins in physiological conditions and increases significantly in cells exposed to heat and a variety of other stressful stimuli (Garrido et al. 2001, 47 Csermely et al. 1998). HSP90 is a unique and central component of machinery that comprises a large number of cofactors, which bind reversibly to HSP90, thus establishing a flexible unit for the conformational control of many different cellular proteins (Schopf et al. 2017). This control includes protein function and activity by facilitating protein folding, the binding of ligands to their receptors or targets, or the assembly of multiprotein complexes (Schopf et al. 2017). Several studies showed that HSP90 can be overexpressed in pathological conditions such as plaques of atherosclerosis and alcoholic liver disease (Ambade et al. 2014). HSP90 is found to be elevated in patients with NAFLD (Rodríguez-Suárez et al. 2010). HSP90 inhibition reduces oxidative stress responses (Madrigal-Matute et al. 2012), indicating that HSP90 inhibitors can be used as therapeutic agents for potential treatment. In the present study, we 
show that the levels of HSP90 in plasma and the liver tissue of rats were related to the type of diet, surgery protocol and interaction between both parameters. The HSP90 plasma and liver levels were higher in the control, SHAM-operated animals when compared to the DJOS procedure. Nevertheless, significantly higher plasma HSP90 levels were observed in the SHAM CD/CD and HFS/CD groups. The baseline of HSP90 levels was significantly increased after SHAM surgery in comparison to DJOS. In our previous studies (Skrzep-Poloczek et al. 2018), we reported that the antioxidant enzymatic systems represented by glutathione peroxidase (GPX), catalase (CAT), superoxide dismutase (CuZnSOD) and nonenzymatic malondialdehyde (MDA) showed a significantly lower level of activity and concentration in the soleus muscle after DJOS surgery in comparison to SHAM-operated animals, and the glutathione reductase (GR) showed significantly increased activity after DJOS in relation to SHAM operation. This may suggest a strong impact of DJOS surgery on the dynamics of antioxidative/oxidative processes. In that study, a change in diet, regardless of the type of diet, stimulated oxidative stress (OS) in DJOS-operated rats. The same type of diet before and after surgery, which was $\mathrm{HF} / \mathrm{HF}$ and $\mathrm{CD} / \mathrm{CD}$, induced OS less than a change in dietary pattern from $\mathrm{HF}$ to $\mathrm{CD}$ or from $\mathrm{CD}$ to HF.

In this study, we would also suggest the potential effect of DJOS in declining the induction of HSP90 levels. The data presented here revealed that the change of the dietary pattern combined with the surgery increased HSP90. The highest impact on HSP90 plasma and liver concentrations came from the HFS diet, both after DJOS and SHAM procedures. Nonetheless, the DJOS procedure was less prone to this amelioration in comparison to the SHAM operation.

These results confirm previous observations that a highenergy, high-carbohydrate and high-fat diet leads to a significant increase in the secretion of HSPs, which can trigger insulin resistance via inhibition of Akt phosphorylation and insulin-mediated GLUT translocation on the cell membrane and ectopic intracellular fat accumulation with NAFLD development (Angelini et al. 2018).

\section{Conclusions}

Bariatric procedures are commonly used in the treatment of obesity and T2DM. Nevertheless, the long-lasting effects of these procedures depend on many factors, among which the diet is one of the most powerful drivers. In order to achieve the expected normalisation of plasma and liver concentrations of HSP70 and HSP90, the DJOS surgery should be applied along with a proper dietary plan. The presence of an HFS diet and the change of the once inducted dietary patterns lead to an increase in HSP70 and HSP90 levels.
Acknowledgments The authors would like to thank to Anna Dulska for illustration and graphic design. Authors would like to express their special gratitude to Mr. Scott Richards for scientific English language correction.

Author contributions DS conceived the idea of this experiment; BS-P, and JM maintained animals; JP, TS conducted the surgery; DS, MK and JJ worked on the manuscript; ECH and DS analysed data and performed statistical analysis; DS and ER carried out analysis. All authors had final approval of the submitted and published version.

Funding This work was funded by the Medical University of Silesia, Poland.

Availability of data and material The original data is available after contact with the corresponding author.

\section{Compliance with ethical standards}

Conflict of interest The authors declare that they have no conflicts of interest.

Ethical approval All applicable institutional and/or national guidelines for the care and use of animals were followed. All animal experimental protocols were approved by the Local Ethics Committee, Poland.

Open Access This article is distributed under the terms of the Creative Commons Attribution 4.0 International License (http:// creativecommons.org/licenses/by/4.0/), which permits unrestricted use, distribution, and reproduction in any medium, provided you give appropriate credit to the original author(s) and the source, provide a link to the Creative Commons license, and indicate if changes were made.

Publisher's note Springer Nature remains neutral with regard to jurisdictional claims in published maps and institutional affiliations.

\section{References}

Alemi H, Khaloo P, Rabizadeh S, Mansournia MA, Mirmiranpour H, Salehi SS, Esteghamati A, Nakhjavani M (2018) Association of extracellular heat shock protein 70 and insulin resistance in type 2 diabetes; independent of obesity and C-reactive protein. Cell Stress Chaperones. https://doi.org/10.1007/s12192-018-0942-x

Ambade A, Catalano D, Lim A, Kopoyan A, Shaffer SA, Mandrekar P (2014) Pharmacological inhibition of heat shock protein 90 alleviates steatosis and macrophage activation in murine acute and chronic alcoholic liver injury. J Hepatol 61(4):903-911. https://doi.org/10. 1016/j.jhep.2014.05.024

Angelini G, Salinari S, Bertuzzi A, Iaconelli A, Mingrone G (2018) Metabolic surgery improves insulin resistance through the reduction of gut-secreted heat shock proteins. Commun Biol 1(69). https://doi. org/10.1038/s42003-018-0069-8

Aroor AR, DeMarco VG (2014) Oxidative stress and obesity: the chicken or the egg? Diabetes 63(7):2216-2218. https://doi.org/10.2337/ $\mathrm{db} 14-0424$

Asea A (2008) Hsp70: a chaperokine. Novartis Found Symp 291:173179 discussion 179-83, 221-4

Atalay M, Oksala N, Lappalainen J, Laaksonen DE, Sen CK, Roy S (2009) Heat shock proteins in diabetes and wound healing. Curr Protein Pept Sci 10(1):85-95 
Breinig M, Caldas-Lopes E, Goeppert B, Malz M, Rieker R, Bergmann F, Schirmacher P, Mayer M, Chiosis G, Kern MA (2009) Targeting heat shock protein 90 with non-quinone inhibitors: a novel chemotherapeutic approach in human hepatocellular carcinoma. Hepatology 50(1):102-112. https://doi.org/10.1002/hep.22912

Buchwald H, Avidor Y, Braunwald E, Jensen MD, Pories W, Fahrbach K, Schoelles K (2004) Bariatric surgery: a systematic review and metaanalysis. JAMA 292:1724-1737

Bukau B, Weissman J, Horwich A (2006) Molecular chaperones and protein quality control. Cell 125:443-451. https://doi.org/10.1016/ j.cell.2006.04.014

Cancello R, Clément K (2006) Is obesity an inflammatory illness? Role of low-grade inflammation and macrophage infiltration in human white adipose tissue. BJOG Int J Obstet Gynaecol 113(10):11411147. https://doi.org/10.1111/j.1471-0528.2006.01004.x

Chung J, Nguyen AK, Henstridge DC (2008) HSP72 protects against obesity-induced insulin resistance. Proc Natl Acad Sci U S A 105: 1739-1744

Csermely P, Schnaider T, Soti C, Prohászka Z, Nardai G (1998) The 90$\mathrm{kDa}$ molecular chaperone family: structure, function, and clinical applications. A comprehensive review. Pharmacol Ther 79:129-168

Furukawa S, Fujita T, Shimabukuro M, Iwaki M, Yamada Y, Nakajima Y, Nakayama O, Makishima M, Matsuda M, Shimomura I (2004) Increased oxidative stress in obesity and its impact on metabolic syndrome. J Clin Invest 114:1752-1761. https://doi.org/10.1172/ JCI21625

Garamvölgyi Z, Prohászka Z, Rigó J, Jr Kecskeméti A, Molvarec A (2015) Increased circulating heat shock protein 70 (HSPA1A) levels in gestational diabetes mellitus: a pilot study. Cell Stress Chaperones 20:575-581. https://doi.org/10.1007/s12192-013-0435-x

Garrido C, Gurbuxani S, Ravagnan L, Kroemer G (2001) Heat shock proteins: endogenous modulators of apoptotic cell death. Biochem Biophys Res Commun 286:433-442. https://doi.org/10.1006/bbrc. 2001.5427

Grueneberger JM, Karcz-Socha I, Marjanovic G, Kuesters S, ZwirskaKorczala K, Schmidt K, Karcz WK (2014) Pylorus preserving loop duodeno-enterostomy with sleeve gastrectomy — preliminary results. BMC Surg 14(1):20. https://doi.org/10.1186/1471-2482-14-20

Gupte AA, Bomhoff GL, Swerdlow RH, Geiger PC, Holmes AG, Chan MH, Mesa JL, Lancaster GI, Southgate RJ, Bruce CR, Duffy SJ, Horvath I, Mestril R, Watt MJ, Hooper PL, Kingwell BA, Vigh L, Hevener A, Febbraio MA (2009) Heat treatment improves glucose tolerance and prevents skeletal muscle insulin resistance in rats fed a high-fat diet. Diabetes 58:567-578. https://doi.org/10.1073/pnas.0705799105

Henstridge DC, Whltham M, Febbralo MA (2014) Chaperoning to the metabolic party: the emerging therapeutic role of heat-shock proteins in obesity and type 2 diabetes. Mol Metab 3:781-793. https:// doi.org/10.1016/j.molmet.2014.08.003

Heydari AR, Wu B, Takahashi R, Strong R, Richardson A (1993) Expression of heat shock protein 70 is altered by age and diet at the level of transcription. Mol Cell Biol 13(5):2909-2918

Kahn SE, Hull RL, Utzschneider KM (2006) Mechanisms linking obesity to insulin resistance and type 2 diabetes. Nature 444:840-846

Karcz WK, Kuesters S, Marjanovic G, Grueneberger JM (2013) Duodeno-enteral omega switches - more physiological techniques in metabolic surgery. Videosurgery Miniinv 8(4):273-279. https:// doi.org/10.5114/wiitm.2013.39647

Lackie RE, Maciejewski A, Ostapchenko VG, Marques-Lopes J, Choy WY, Duennwald ML, Prado VF, Prado MAM (2017) The Hsp70/ Hsp90 chaperone machinery in neurodegenerative diseases. Front Neurosci 16(11):254. https://doi.org/10.3389/fnins.2017.00254

Li W, Tsen F, Sahu D, Bhatia A, Chen M, Multhoff G, Woodley DT (2013) Extracellular Hsp90 (eHsp90) as the actual target in clinical trials: intentionally or unintentionally. Int Rev Cell Mol Biol 303: 203-235. https://doi.org/10.1016/B978-0-12-407697-6.00005-2
Madrigal-Matute J, Fernandez-Garcia CE, Gomez-Guerrero C, LopezFranco O, Muñoz-Garcia B, Egido J, Blanco-Colio LM, MartinVentura JL (2012) HSP90 inhibition by 17-DMAG attenuates oxidative stress in experimental atherosclerosis. Cardiovasc Res 95(1): 116-123. https://doi.org/10.1093/cvr/cvs158

Makki K, Froguel P, Wolowczuk I (2013) Adipose tissue in obesityrelated inflammation and insulin resistance: cells, cytokines, and chemokines. ISRN Inflamm 5091:139-239

Morteza A, Nakhjavani M, Larry M, Nargesi AA, Esteghamati A (2013) Heat shock protein 70 and albuminuria in patients with type 2 diabetes: a matched case control study. Cell Stress Chaperones 18(6): 815-819. https://doi.org/10.1007/s12192-013-0435-x

Mosinski JD, Pagadala MR, Mulya A, Huang H, Dan O, Shimizu H, Batayyah E, Pai RK, Schauer PR, Brethauer SA, Kirwan JP (2016) Gastric bypass surgery is protective from high-fat diet-induced non-alcoholic fatty liver disease and hepatic endoplasmic reticulum stress. Acta Physiol 217:141-151

Moura CS, Lollo PCB, Morato PN, Carneiro EM, Amaya-Farfan J (2013) Whey protein hydrolysate enhances the exercise-induced heat shock protein (HSP70) response in rats. Food Chem 136(3-4):1350-1357. https://doi.org/10.1016/j.foodchem.2012.09.070

Moura CS, Lollo PCB, Morato PN, Amaya-Farfan J (2018) Dietary nutrients and bioactive substances modulate heat shock protein (HSP) expression: a review. Nutrients 10:683. https://doi.org/10.3390/ nu10060683

Myung SJ, Yoon JH, Kim BH, Lee JH, Jung EU, Lee HS (2009) Heat shock protein 90 inhibitor induces apoptosis and attenuates activation of hepatic stellate cells. J Pharmacol Exp Ther 330(1):276-282

Nakhjavani M, Morteza A, Khajeali L, Esteghamati A, Khalilzadeh O, Asgarani F, Outeiro TF (2010) Increased serum HSP70 levels are associated with the duration of diabetes. Cell Stress Chaperones 15: 959-964. https://doi.org/10.1007/s12192-010-0204-z

Nakhjavani M, Morteza A, Asgarani F, Khalilzadeh O, Ghazizadeh Z, Bathaie SZ, Esteghamati A (2012) The dual behavior of heat shock protein 70 and asymmetric dimethylarginine in relation to serum CRP levels in type 2 diabetes. Gene 498(1):107e11. https://doi. org/10.1016/j.gene.2012.01.085

Nauck MA (2009) Unraveling the science of incretin biology. Am J Med 122(6):S3-S10

O'Keefe HJ, Gheewala NM, O'Keefe O (2008) Dietary strategies for improving post-prandial glucose, lipids, inflammation, and cardiovascular health. J Am Coll Cardiol 51(3):249-255. https://doi.org/ 10.1016/j.jacc.2007.10.016

Poudyal H, Sunil P, Lindsay B (2010) Comparison of purple carrot juice and b-carotene in a high-carbohydrate, high-fat diet-fed rat model of the metabolic syndrome. Br J Nutr 104:1322-1332. https://doi.org/ $10.1017 / \mathrm{S} 0007114510002308$

Pratt WB, Toft DO (2003) Regulation of signaling protein function and trafficking by the hsp90/hsp70-based chaperone machinery. Exp Biol Med (Maywood) 228:111-133

Rocha V, Folco E, Sukhova G, Shimizu K, Gotsman I, Vernon A, Libby P (2008) Interferon-gamma, a Thl cytokine, regulates fat inflammation: a role for adaptive immunity in obesity. Circ Res 103(5):467476. https://doi.org/10.1161/CIRCRESAHA.108.177105

Rodríguez-Suárez E, Duce AM, Caballería J, Martínez Arrieta F, Fernández E, Gómara C, Alkorta N, Ariz U, Martínez-Chantar ML, Lu SC, Elortza F, Mato JM (2010) Non-alcoholic fatty liver disease proteomics. Proteomics Clin 4(4):362-371. https://doi.org/ $10.1002 /$ prca.200900119

Rohde M, Daugaard M, Jensen MH, Helin K, Nylandsted J, Jaattela M (2005) Members of the heat-shock protein 70 family promote cancer cell growth by distinct mechanisms. Genes Dev 19(5):570-582. https://doi.org/10.1101/gad.305405

Rubino F, Gagner M (2002) Potential of surgery for curing type 2 diabetes mellitus. Ann Surg 236(5):554-559 
Rubino F, Forgione A, Cummings DE, Vix M, Gnuli D, Mingrone G, Castagneto M, Marescaux J (2006) The mechanism of diabetes control after gastrointestinal bypass surgery reveals a role of the proximal small intestine in the pathophysiology of type 2 diabetes. Ann Surg 244(5): 741-749. https://doi.org/10.1097/01.sla.0000224726.61448.1b

Rubino F, Schauer PR, Kaplan LM, Cummings DE (2010) Metabolic surgery to treat type 2 diabetes: clinical outcomes and mechanisms of action. Annu Rev Med 61:393-411. https://doi.org/10.1146/ annurev.med.051308.105148

Russell WMS, Burch RL (1959) The principles of humane experimental technique. Methuen Co., LTD, London

Schopf FH, Biebl MM, Buchner J (2017) The HSP90 chaperone machinery. Nat Rev Mol Cell Biol 18:345-360. https://doi.org/10.1038/ nrm.2017.20

Shukla HD, Pitha PM (2012) Role of hsp90 in systemic lupus erythematosus and its clinical relevance. Autoimmune Dis 2012:728605. https://doi.org/10.1155/2012/728605

Silver JT, Noble EG (2012) Regulation of survival gene hsp70. Cell Stress Chaperones 17(1):1-9. https://doi.org/10.1007/s12192-0110290-6

Skrzep-Poloczek B, Stygar D, Chełmecka E, Nabrdalik K, Romuk E, Poloczek J, Sawczyn T, Karcz KW, Gumprecht J (2018) Antioxidant status in the soleus muscle of Sprague-Dawley rats in relation to duodenal-jejunal omega switch and different dietary patterns. Oxid Med Cell Longev. Volume 2018, Article ID 3795070, 12 pages. https://doi.org/10.1155/2018/3795070

Stefater MA, Wilson-Perez HE, Chambers AP, Sandoval DA, Seeley RJ (2012) All bariatric surgeries are not created equal: insights from mechanistic comparisons. Endocr Rev 33:595-622. https://doi.org/ 10.1210/er.2011-1044

Stygar D, Sawczyn T, Skrzep-Poloczek B, Karcz-Socha I, Doleżych B, Zawisza-Raszka A, Augustyniak M, Żwirska-Korczala K, Karcz WK (2015) Ileal transposition in rats influenced glucose metabolism and HSP70 levels. Open Life Sci 10:278-284. https://doi.org/10. 1515/biol-2015-0029

Stygar D, Sawczyn T, Skrzep-Poloczek B, Owczarek AJ, Matysiak N, Michalski M, Mielańczyk Ł, Bażanów B, Ziora P, Choręza P, Doleżych B, Karcz KW (2018) The effects of duodenojejunal omega switch in combination with high-fat diet and control diet on incretins, body weight, and glucose tolerance in Sprague-Dawley rats. Obes Surg 28(3):748-759. https://doi.org/10.1007/s11695017-2883-3

Traverso LW, Longmire WP Jr (1978) Preservation of the pylorus in pancreaticoduodenectomy. Surg Gynecol Obstet 146(6):959-962

Trepel J, Mollapour M, Giaccone G, Neckers L (2010) Targeting the dynamic HSP90 complex in cancer. Nat Rev Cancer 10(8):537549. https://doi.org/10.1038/nrc2887

Tukaj S, Kleszczyński K, Vafia K, Groth S, Meyersburg D, Trzonkowski P, Ludwig RJ, Zillikens D, Schmidt E, Fischer TW, Kasperkiewicz M (2013) Aberrant expression and secretion of heat shock protein 90 in patients with bullous pemphigoid. PLoS One 8(7):e70496. https://doi.org/10.1371/journal.pone.0070496

Whitley D, Goldberg SP, Jordan WD (1999) Heat shock proteins: a review of the molecular chaperones. J Vasc Surg 29:748-751 